\title{
ADIPONECTIN IN PATIENTS WITH VARIOUS STAGES OF CORONARY HEART DISEASE - COMPARISON OF ITS CONCENTRATION IN CORONARY ARTERIES AND PERIPHERAL VENOUS CIRCULATION
}

\author{
David Stejskal ${ }^{\mathrm{a}}$, Josef Bartek \\ a Department of Laboratory Medicine, Hospital Šternberk, Jivavská 20, 785 16, Šternberk, Czech Republic \\ $b \quad$ Institute of Medical Chemistry and Biochemistry, Faculty of Medicine, Palacký University Olomouc, Hnèvotínská 3, \\ 775 15, Olomouc, Czech Republic
}

Received: October 20, 2003; Accepted (with revisions): December 12, 2003

Key words: Adiponectin / Coronary Heart Disease/ Acute Coronary Syndrom / Atherosclerosis

Adiponectin is an adipocytes-produced protein and showing a number of antiatherogenic effects. Adiponectin sems to be extensively deposited in the intersticium of venous lesions of persons with myocardial infarction. It may exhibit antiatherogenic and reparative effects. A decreased adiponectin concentration may be a risk factor of the origin and complications of atherosclerosis.

Aim of the study: 1) Do the adiponectin concentrations in venous blood of persons with acute coronary syndrome (ACS) differ from those in persons with stress angina pectoris? 2) In these persons do adiponectin concentrations in venous blood differ from those in main coronary arteries? 3) Do adiponectin levels differ in the infarction and non-infarction arteries in persons with STEMI (ST Elevation Myocardial Infarct) and delay within 4 hours after the onset? 4) In persons with ACS does any correlation exist between venous adiponectin and common risk factors of cardiovascular complications? Adiponectin concentration was determined in samples of blood collected from the peripheral vein and during coronarography in various localizations in 4 groups of examined persons (I. - no signs of CAD, II. - stable stress angina pectoris, III. - ACS over 48 hours without elevations of ST segment, IV. - STEMI during first 4 hours after its origin and proved occlusion of coronary artery at coronarography). Coronary angiography, risk factors and anamnestic data were analyzed. The software Medcalc was used to perform statistical analysis.

We examined 73 probands with signs of myocardial ischemia (mean age of 61.5 years, $64 \%$ males), who were subjected to coronarography and 21 healthy volunteers. A mean delay (delay from the origin of complaints to the performed coronarography) was $3.1 \pm 0.5$ hours in individuals in the group IV. In patients with ACS we found lower adiponectin concentrations in venous blood compared to healthy individuals and persons with stress AP, but changes were not statistically significant (I.: $-5.9 \pm 2.7 \mathrm{ng} / 1$, II.: $-4.9 \pm 1.2 \mathrm{ng} / 1$, III.: $-5.2 \pm 4.1 \mathrm{ng} / 1$, IV.: $-4.6 \pm 2.7 \mathrm{ng} / 1$ ); no differences were found also with BMI. No significant difference was recorded between the samples of venous blood and those of coronary arteries, nor between the infarction and the non-infarction arteries in the group IV. (5.2 $\pm 2.6 \mathrm{ng} / 1$ vs. $4.8 \pm-2.7 \mathrm{ng} / 1)$. Significant negative correlations were observed between adiponectin concentrations and BMI (correlation coefficient -0.29), triacylglycerols (correlation coefficient -0.4), AOPP (correlation coefficient -0.39), and positive correlations with HDL (correlation coefficient 0.32 ). No correlation was recorded between adiponectin and CRP. Adiponectin concentrations in persons with ACS are lower than in healthy persons or patients with stable angina pectoris, but differences are not statistically significant. The absence of adiponectin differences between the infarction/non-infarction artery may support the hypothesis of adiponectin uptake in the ischemic lesion with subsequent decrease in blood adiponectin. On the contrary, adiponectin decrease may be a risk factor independent of the origin and development of ACS.

\section{INTRODUCTION}

Adiponectin is an adipocytokin with numerous antiatherogenic properties. Its antiatherogenic effect is mediated through its binding ability to collagen (is accumulated in damaged arteries and has a potential antiatherogennic effect).

Referring to several recent papers reporting that adiponectin is localized in the interstice of infarction lesions and considerably affects (decreases) expression of adhesive molecules production of growth factors and cytokines thus displaying the anthiatherogenic effect, we decided to aswer the following questions:

- Does adiponectin concentration differ in persons with acute coronary syndrome from that in patients with stable angina pectoris and from healthy individuals?

- Does adiponectin concentration in venous blood differ from that in main coronary arteries? 
- Does adiponectin concentration in persons with acute myocardial infarction differ in the infarction and the non-infarction artery?

- Does any correlation exist between adiponectin and common risk factors of cardiovascular complications?

\section{METHODS}

We examined 73 probands, patients of the Angiographic Center of the $1^{\text {st }}$ Department of Internal Medicine, University Hospital Olomouc, who were subjected to coronary angiography according to common indication criteria, and 21 healthy individuals without clinical and anamnestic signs of coronary artery disease (CAD).

Persons under study were divided into 4 groups: The group "I." consisted of probands without CAD signs, the group "II." comprised individuals with stable stress angina pectoris, the group "III." consisted of persons with acute coronary syndrome over 48 hours without ST segment elevations, the group "IV." comprised patients with acute myocardial infarction and ST segmentu elevation (STEMI) during first 4 hours after its origin and confirmation of occlusion of coronary artery at coronarography.

In all persons under study, the following parameters were determined in peripheral venous blood: AOPP (according to Witko-Sarsat, ELISA line Marc+Max), adiponectin (ELISA sandwich, Biovendor), cholesterol (enzyme, BioVendor), HDL (direct assay, BioVendor), triacylglycerols (enzyme, BioVendor), glucose (enzyme, Lachema), cTnI (LEIA, DPC), HbA1c (HPLC affinitive boronate, Primus), creatinin (Jaffe), urea (enzyme, BioVendor), ALT (IFCC, BioVendor), AST (IFCC, BioVendor), CRP ultrasensitive (LEIA, DPC), blood count (Coulter).

In persons subjected to coronary angiography, we collected blood samples from the right and the left coronary arteries and determined adiponectin. Catheter insertion in coronary artery was checked-up and $5 \mathrm{ml}$ of blood was removed from the catheter to prevent mixing with aorta blood, then 5-7 $\mathrm{ml}$ of blood was collected from coronary artery for next analysis.

In all subjects their anamnesis was taken to find out the cardiovascular risks and complications, therapy, actual blood pressure and body mass index (BMI) was calculated. Patients in the groups "II."-"IV." were subjected to echocardiography and the left ventricle ejection fraction (LVEF) was calculated using Simpson method, in persons of the groups "III.-IV.” LVEF was determined also at ventriculography.

Coronary angiography carried out via the left femoral artery $6 \mathrm{~F}$ or by a $7 \mathrm{~F}$ instrument. Evaluation of coronary artery occlusion stenose significance was performed by an invasive cardiologist who was not aware of about patient's further risks. All patients in the group "II." (stable angina pectoris) were found at coronarography to have at least one stenosis narrowing the lumen by over $60 \%$.

All data were processed by SPSS software for Windows and Medcalc. Connected quantities are expressed as mean \pm standard deviation, unless stated otherwise. Adiponectin concentrations in groups were compared by the method of distribution analysis (ANOVA, Kruskal Wallis tests), by means of non-parametric Student $t$ tests and ROC analysis. Adiponectin concentrations and other quantities were mutually correlated using Spearmann correlation coefficient. Category data were compared by $\chi^{2}$ test. The value $\mathrm{p}<0.05$ was considered as statistically significant.

\section{RESULTS}

We examined a total of 94 probands of mean age of 61.5 years (64\% men and $36 \%$ women). In $18 \%$ individuals were recorded heart failure, $21 \%$ had myocardial infarction in anamnesis, $7 \%$ persons underwent revascularization in anamnesis, $14 \%$ were active smokers, $71 \%$ had been treated for hypertension and $29 \%$ for diabetes mellitus. A mean delay (delay from the onset of complaints to the performed coronary angiography) represented in persons in the group "IV" $3.1 \pm 0.5$ hours.

Other data of patients in individual groups are given in Table 1.

Adiponectin concentration in healthy individuals in the control group "I." (5.9 $\pm 2.7 \mathrm{ng} / \mathrm{l})$ did not differ significantly from that in patients of the group "II." ( $4.9 \pm 1.2 \mathrm{ng} / 1)$, group "III." (5.2 $\pm 4.1 \mathrm{ng} / \mathrm{l})$ and the group "IV." (4.6 $\pm 2.7 \mathrm{ng} / \mathrm{l})$; values did not differ also in BMI (Table 2, Graph 1).

It was found that adiponectin concentrations in peripheral venous blood and arterial blood did not differ significantly and showed a significant correlation (correlation coefficient $0.89, \mathrm{p}<0.001$ ) (Table 3 ).

In the group "IV." no significant difference was found between adiponectin concentrations in infarction and non-infarction arteries $(5.2 \pm 2.6 \mathrm{ng} / 1$ vs. $4.8 \pm 2.7 \mathrm{ng} / \mathrm{l})$.

The whole set under study showed significant negative correlations between adiponectin concentration and BMI (correlation coefficient -0.29), triacylglycerols (correlation coefficient -0.4), AOPP (correlation coefficient -0.39 ) and positive correlation with HDL (correlation coefficient 0.32) (Table 4). No correlations were recorded between adiponectin levels and CRP, nicotinism, left ventricle ejection fraction, other parameters of metabolism of glucose, lipids or nitrogen metabolites. 
Table 1. Basic characteristics of persons under study (mean \pm SD).

\begin{tabular}{|l|c|c|c|c|}
\hline Parameter & Group I & Group II & Group III & Group IV \\
\hline No. of persons & 21 & 23 & 28 & 22 \\
\hline Age (years) & $50 \pm 14$ & $62 \pm 10$ & $67 \pm 9$ & $66 \pm 9$ \\
\hline Men/Women & $10 / 11$ & $15 / 8$ & $18 / 10$ & $15 / 7$ \\
\hline Dyslipidemia & $5(24 \%)$ & $15(65 \%)$ & $14(50 \%)$ & $8(36 \%)$ \\
\hline Hypertension & $7(33 \%)$ & $20(87 \%)$ & $23(82 \%)$ & $17(77 \%)$ \\
\hline DM & $1(5 \%)$ & $8(35 \%)$ & $12(43 \%)$ & $6(27 \%)$ \\
\hline Smoker & $3(14 \%)$ & $1(4 \%)$ & $5(18 \%)$ & $4(18 \%)$ \\
\hline BMI & $23.9 \pm 3.5$ & $28.4 \pm 3.4$ & $28.9 \pm 3.5$ & $26.9 \pm 3.1$ \\
\hline Revascular. & 0 & $5(22 \%)$ & $1(4 \%)$ & $1(5 \%)$ \\
\hline
\end{tabular}

Revascular. revascularisation in anamnesis

Table 2. Adiponectin (ADP) values in individual groups according to diagnosis, ng/1.

\begin{tabular}{|c|c|c|c|c|c|}
\hline Groups & $\mathrm{n}$ & $\mathrm{X}$ & Median & SD & Median ADP/BMI \\
\hline Healthy & 21 & 5.9 & 5.1 & 2.7 & 0.19 \\
\hline STAP & 23 & 4.9 & 4.7 & 2.3 & 0.16 \\
\hline ACS $>48$ & 28 & 4.4 & 4.5 & 2.0 & 0.16 \\
\hline ACS $<48$ & 22 & 4.8 & 4.0 & 3.0 & 0.17 \\
\hline ACS & 50 & 4.6 & 4.1 & 2.6 & 0.16 \\
\hline
\end{tabular}

ACS $>48$ acute coronary syndrome over 48 hours

ACS $<48$ acute coronary syndrome below 48 hours

ACS acute coronary syndrome (comprises the older and younger ACS)

STAP stable angina pectoris

Table 3. Adiponectin concentrations in individual groups according to the site of sample collection, $\mathrm{n}=73$ (groups “II.”, “III.”, “IV.”).

\begin{tabular}{|c|c|c|c|}
\hline Groups & X & Median & SD \\
\hline Vein & 5.1 & 4.5 & 3.2 \\
\hline ACL & 5.2 & 4.7 & 3.1 \\
\hline ACR & 5.0 & 4.8 & 3.7 \\
\hline
\end{tabular}

Vein adiponectin concentration in the cubital vein

ACL adiponectin concentration in the left coronary artery

ACR adiponectin concentration in the right coronary artery

SD standard deviation 
Table 4. Significant correlations between adiponectin and other measured parameters.

\begin{tabular}{|c|c|c|c|l|}
\hline Parameter1 & Parameter2 & Cor. coef. & \multicolumn{1}{|c|}{$\mathrm{p}$} & \multicolumn{1}{|c|}{$95 \%$ CI } \\
\hline AN & BMI & -0.29 & 0.05 & $:-0.56:-0.2$ \\
& Trg & -0.4 & 0.04 & $:-0.6: 0.01$ \\
& AOPP & -0.39 & 0.016 & $:-0.62:-0.08$ \\
& HDL & 0.32 & 0.05 & $: 0.05:-0.62$ \\
\hline
\end{tabular}

AN adiponectin

Trg triacylglycerols

HDL high density lipoproteins cholesterol

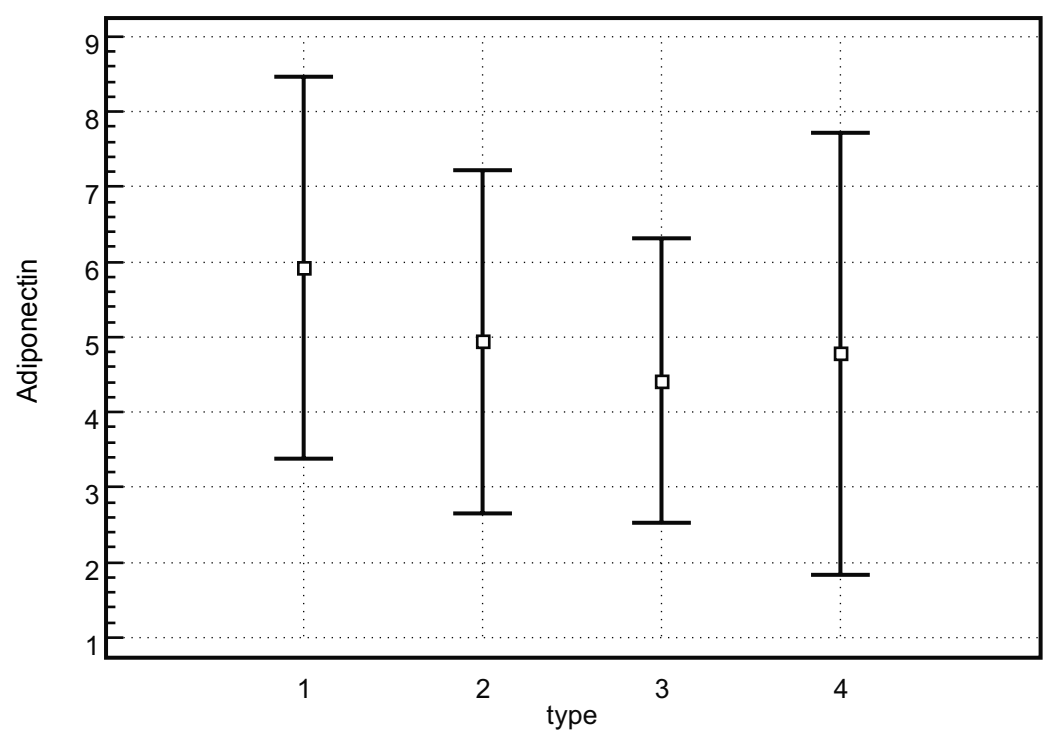

Adiponectin and the Patient groups (Means $\pm S D$ )

\section{Graph 1}

1 Healthy individuals

2 Stress angina pectoris

3 Acute coronary syndrome over 48 hours without ST segment elevations

4 Acute myocardial infarction with ST segment elevation (STEMI)

\section{DISCUSSION}

Highly interesting are papers reporting that adiponectin is accumulated particularly in the involved veins (more frequently than in intact veins) around macrophages where it suppresses their transformation, endothelial inflammatory response, expression of adhesive molecules and production of some cytokines, as well as proliferation of smooth muscle cells ${ }^{4}$.

The hypothesis on the role of adiponectin in atherosclerosis is also supported by the studies on autobioptic myocardial samples where adiponectin (GBP28) was localized in the interstice of infarction lesions and in their vicinity even in the early stage of coronary necrosis; but was absent in a scar after necrosis.

In 2003, a communication appeared on a significant reduction of adiponectin during 72 hours after admission to the coronary unit. Level became normal in the course of 1-4 weeks and correlated with CRP concentration.

Mechanism of adiponectin reduction after coronary attack has not been elucidated yet. This may occur after rupture of atherosclerotic plates where it is deposited. Another possibility is that an inflammatory process (and subsequent plate rupture) occurs primarily in subjects with decreased adiponectin concentration prior to myocardial infarction and these decreased adiponectin concentrations lead to the origin of AMI. 
It cannot be excluded that adiponectin may function as a "destroyer" of a newly formed collagen after ischemic impairment and thus positively affects vascular remodeling. The evidence of adiponectin (GBP28) in vascular walls may be theoretically useful in the assessment of patient's prognosis (its presence may indicate a favorable prognosis $)^{14}$. In this respect, therapeutical approaches are also speculated when intervention made for increased blood adiponectin may eliminated frequency of restenoses of coronary arteries (e.g. after regime measures or administration of drugs resulting in adiponectin increase ${ }^{14}$ ).

With regard to the aforementioned facts we believed that the assessment of adiponectin in blood from coronary arteries (infarction/non-infarction artery) could contribute to elucidation of this phenomenon.

Referring to sporadic literary data we expected that adiponectin levels in persons with acute coronary syndrome would differ from those in patients with stress angina pectoris or those in healthy individuals. Although different adiponectin levels were found in our groups under study, the differences were not statistically significant. This might be due to many reasons, e.g. adiponectin concentrations differ significantly according to severity of coronary disease so that our groups were not homogenous. Another reason could be a short delay from the onset of complaints to the performance of coronarography in subjects with AIM (group "IV."); if the hypothesis on deposits of adiponectin into ruptured atherosclerotic plates is correct, a significant decrease occurs during 24 hours after the origin of coronary attack, so that in our study no significant decrease of adiponectin appeared.

We also expected in the group of patients with ACS any differenced between adiponectin concentrations in the infarction/non-infarction arteries. The absence of the expected differences could indicate the following facts: 1) uptake of adiponectin in ischemic lesion does not affect significantly a local adiponectin concentration in the blood due to other factors involved, or 2) the hypothesis on significant uptake of adiponectin leading to reduced adiponectin concentration in the blood is not correct, or 3 ) with regard to a shor delay between the onset of complaints and performance of coronarography no significant deposit of adiponectin into vascular walls occurred so that its concentration in coronary arteries was not changed.

We confirmed literary data on negative correlations between adiponectin concentration and BMI value (even in patients with ACS), concentration of triacylglycerols, AOPP and positive correlation with BMI. These findings indicate that the changed adiponectin levels are associated with the presence of risk factors of metabolic syndrome.

The absence of negative correlation between concentrations of CRP and adiponectin, described by Kojima et al. ${ }^{20}$ in individuals in the course of several hours (days) after the origin of acute myocardial infarction could be due to the fact that subjects with STEMI had a very short delay so that neither CRP elevation nor adiponectin reduction could occur; persons in other groups had a low CRP concentration, so that the above correlations could not be recorded.

\section{CONCLUSION}

Adiponectin concentration in persons with ACS did not differ from that in patients with stable AP and from healthy volunteers. Adiponectin concentrations in peripheral venous blood and arterial blood also did not differ. We found no significant difference between adiponectin concentrations in infarction and non-infarction arteries. We found negative correlations between adiponectin concentration and BMI, triacylglycerols, AOPP and positive correlation with HDL.

The hypothesis stipulating that adiponectin decrease in patients with acute coronary syndrome is caused by its enhanced uptake in ruptures of atherosclerotic plates has not been confirmed yet.

\section{ACKNOWLEDGEMENT}

The study was supported by the grant MSM 151100003 from the Ministry of Youth and Education of the Czech Republic.

\section{REFERENCES}

1. Ishikawa Y, Akasaka Y, Ishii T, Yoda-Murakami M, Choi-Miura NH, Tomita M, Ito K, Zhang L, Akishima Y, Ishihara M, Muramatsu M, Taniyama M. (2003) Changes in the distribution pattern of gelatin-binding protein of $28 \mathrm{kDa}$ (adiponectin) in myocardial remodelling after ischaemic injury. Histopathology 42, 43-52.

2. Motoshima H, Wu X, Sinha MK, Hardy VE, Rosato EL, Barbot DJ, Rosato FE, Goldstein BJ. (2002) Differential regulation of adiponectin secretion from cultured human omental and subcutaneous adipocytes: effects of insulin and rosiglitazone. J Clin Endocrinol Metab 87, 5662-5667.

3. Mallamaci F, Zoccali C, Cuzzola F, Tripepi G, Cutrupi S, Parlongo S, Tanaka S, Ouchi N, Kihara S, Funahashi T, Matsuzawa Y. (2002) Adiponectin in essential hypertension. J Nephrol 15, 507-511.

4. Okamoto Y, Kihara S, Ouchi N, Nishida M, Arita Y, Kumada M, Ohashi K, Sakai N, Shimomura I, Kobayashi H, Terasaka N, Inaba T, Funahashi T, Matsuzawa Y. (2002) Adiponectin reduces atherosclerosis in apolipoprotein E-deficient mice. Circulation 106, 2767-2670.

5. Ukkola O, Santaniemi M. (2002) Adiponectin: a link between excess adiposity and associated comorbidities? J. Mol. Med. 80, 696-702.

6. Yu S, Matsusue K, Kashireddy P, Cao WQ, Yeldandi V, Yeldandi AV, Rao MS, Gonzalez FJ, Reddy JK. (2003) Adipocyte-specific Gene Expression and Adipogenic Steatosis in the Mouse Liver Due to Peroxisome Proliferator-activated Receptor gamma 1 (PPARgamma 1) Overexpression. J Biol Chem 278, 498-505.

7. Makimura H, Mizuno TM, Bergen H, Mobbs CV. (2002) Adiponectin is stimulated by adrenalectomy in ob/ob mice and is highly correlated with resistin mRNA. Am J Physiol Endocrinol Metab 286, 1266-1271.

8. Lihn AS, Ostergard T, Nyholm B, Pedersen SB, Richelsen B, Schmitz O. (2003) Adiponectin expression in adipose tissue is reduced in first-degree relatives of type 2 diabetic patients. Am J Physiol Endocrinol Metab 284, E443-E448.

9. Stefan N, Stumvoll M. Horm (2002) Adiponectin-its role in metabolism and beyond. Metab Res 34, 469-474.

10. Stefan N, Vozarova B, Funahashi T, Matsuzawa Y, Ravussin E, Weyer C, Tataranni PA (2002) Plasma adiponectin levels are not associated with fat oxidation in humans. Obes Res 10, 1016-1020. 
11. Yamauchi T, Kamon J, Minokoshi Y, Ito Y, Waki H, Uchida S, Yamashita S, Noda M, Kita S, Ueki K, Eto K, Akanuma Y, Froguel P, Foufelle F, Ferre P, Carling D, Kimura S, Nagai R, Kahn BB, Kadowaki T. (2002) Adiponectin stimulates glucose utilization and fatty-acid oxidation by activating AMP-activated protein kinase. Nat Med 8, 1288-1295.

12. Wagner JA. (2002) Overview of biomarkers and surrogate endpoints in drug development. Dis Markers 18, 41-46.

13. Javorschi S, Hevener AL, Kruszynska YT, Norman RA, Sinha M, Olefsky JM. (2002) The effect of thiazolidinediones on plasma adiponectin levels in normal, obese, and type 2 diabetic subjects. Diabetes 51, 2968-2974.

14. Matsuda M, Shimomura I, Sata M, Arita Y, Nishida M, Maeda N, Kumada M, Okamoto Y, Nagaretani H, Nishizawa H, Kishida K, Komuro R, Ouchi N, Kihara S, Nagai R, Funahashi T, Matsuzawa Y. (2002) Role of adiponectin in preventing vascular stenosis. The missing link of adipo-vascular axis. J Biol Chem 277 , 37487-37491.

15. Shimada K, Miyauchi K, Mokuno H, Miyazaki T, Seki E, Watanabe Y, Iwama Y, Shigekiyo M, Matsumoto M, Okazaki S, Tanimoto K, Kawamura M, Suzuki H, Kurata T, Sato H, Daida H. (2002) Predictive value of the adipocyte-derived plasma protein adiponectin for restenosis after elective coronary stenting. Jpn Heart J 43, 85-91
16. Ouchi N, Kihara S, Arita Y, Nishida M, Matsuyama A, Okamoto Y, Ishigami M, Kuriyama H, Kishida K, Nishizawa H, Hotta K, Muraguchi M, Ohmoto Y, Yamashita S, Funahashi T, Matsuzawa Y. (2001) Adipocyte-derived plasma protein, adiponectin, suppresses lipid accumulation and class A scavenger receptor expression in human monocyte-derived macrophages. Circulation 103, 1057-1063.

17. Ouchi N, Kihara S, Arita Y, Okamoto Y, Maeda K, Kuriyama H, Hotta K, Nishida M, Takahashi M, Muraguchi M, Ohmoto Y, Nakamura T, Yamashita S, Funahashi T, Matsuzawa Y. (2000) Adiponectin, an adipocyte-derived plasma protein, inhibits endothelial NF-kappaB signaling through a cAMP-dependent pathway. Circulation 102, 1296-1301.

18. Yokota T, Oritani K, Takahashi I, Ishikawa J, Matsuyama A, Ouchi N, Kihara S, Funahashi T, Tenner AJ, Tomiyama Y, Matsuzawa Y. (2000) Adiponectin, a new member of the family of soluble defense collagens, negatively regulates the growth of myelomonocytic progenitors and the functions of macrophages. Blood 96, 172.

19. Scherer PE, Williams S, Fogliano M, Baldini G, Lodish HF. (1995) A novel serum protein similar to C1q, produced exclusively in adipocytes. J Biol Chem 270, 26746-26749.

20. Kojima S, Funahashi T, Sakamoto T. (2003) The variation of plasma concentrations a novel adipocyte derived protein, adiponektin, in patiens with acute myocardial infarction. Heart 89, 377-381. 